Classification

Physics Abstracts

$61.30 \mathrm{E}-64.70 \mathrm{M}$

\title{
Experimental studies on a triply reentrant mesogen
}

\author{
R. Shashidhar, B. R. Ratna, V. Surendranath, V. N. Raja, S. Krishna Prasad \\ and C. Nagabhushan
}

Raman Research Institute, Bangalore 560080, India

(Reçu le 8 février 1985, accepté le 25 mars 1985)

\begin{abstract}
Résumé. - Nous présentons les résultats d'études optiques, aux rayons $X$, diélectrique et haute pression sur le 4-nonyloxyphényl-4'-nitrobenzoyloxybenzoate $\left(\mathrm{DB} 90 \mathrm{NO}_{2}\right)$, composé réentrant triple qui présente la séquence suivante de transitions en refroidissant à partir de la phase isotrope à pression atmosphérique : $\mathrm{I}-\mathrm{N}-\mathrm{A}_{\mathrm{d}}-\mathrm{N}_{\mathrm{re}}-\mathrm{A}_{\mathrm{d}(\mathrm{re})}-\mathrm{N}_{\mathrm{re}}-\mathrm{A}_{1}-\tilde{\mathrm{C}}-\mathrm{A}_{2}-\mathrm{C}_{2}$. Ces études révèlent bien l'existence de la phase $A_{2}$ non mentionnée jusqu'ici dans ce composé.
\end{abstract}

\begin{abstract}
We present here the results of our detailed optical, X-ray, high pressure and dielectric studies on 4-nonyloxyphenyl-4'-nitrobenzoyloxybenzoate $\left(\mathrm{DB} 90 \mathrm{NO}_{2}\right)$, a triply reentrant compound which exhibits the following sequence of transitions at atmospheric pressure on cooling the isotropic phase : I-N-A $A_{d}-N_{r e}-A_{d(r e)}-N_{r e}-A_{1}-\tilde{C}-A_{2}-C_{2}$. The existence of the $A_{2}$ phase, not reported so far in this compound, is clearly shown from our studies.
\end{abstract}

\section{Introduction.}

The discovery of reentrant nematic behaviour [1-3] in compounds whose constituent molecules possess a strongly polar cyano end group has led to considerable activity in the synthesis of a large number of terminally cyano- and nitro-substituted triaromatic compounds [4]. This resulted in the observation of a variety of polar smectic $A$ and smectic $C$ phases, and of several unusual sequences of polymorphic transitions [5]. Perhaps the most remarkable sequence seen so far in a polar mesogen is the following seen recently by the Bordeaux Group in 4-nonyloxyphenyl-4'-nitrobenzoyloxybenzoate or $\mathrm{DB} 90 \mathrm{NO}_{2}[6]$ :

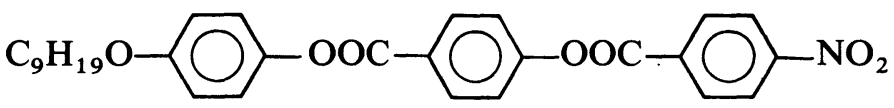

$\mathrm{I}-\mathrm{N}-\mathrm{A}_{\mathrm{d}}-\mathrm{N}_{\mathrm{re}}-\mathrm{A}_{\mathrm{d}(\mathrm{re})}-\mathrm{N}_{\mathrm{re}}-\mathrm{A}_{1}-\widetilde{\mathrm{C}}-\mathrm{C}_{2}$.

Since the nematic phase reenters twice and the partially bilayer $A_{d}$ phase once, this compound has been referred to as the triply reentrant mesogen. We have carried out detailed microscopic, $\mathrm{X}$-ray, high pressure and dielectric studies of this compound. These results show the existence of an additional phase, viz. $A_{2}$, between the $\widetilde{C}$ and $C_{2}$ phases, the transition temperatures of our 
sample being : $\mathrm{N} \stackrel{195 \mathrm{~K}}{\longrightarrow} \mathrm{A}_{\mathrm{d}} \stackrel{156 \mathrm{~K}}{\longrightarrow} \mathrm{N}_{\mathrm{re}} \stackrel{138.5 \mathrm{~K}}{\longrightarrow} \mathrm{A}_{\mathrm{d}(\mathrm{re})} \stackrel{124 \mathrm{~K}}{\longrightarrow} \mathrm{N}_{\mathrm{re}} \stackrel{121.5 \mathrm{~K}}{\longrightarrow} \mathrm{A}_{1} \stackrel{119 \mathrm{~K}}{\longrightarrow} \widetilde{\mathrm{C}} \stackrel{100 \mathrm{~K}}{\longrightarrow}$ $\mathrm{A}_{2} \stackrel{96 \mathrm{~K}}{\longrightarrow} \mathrm{C}_{2}$.

\section{Experimental.}

$\mathrm{X}$-ray diffraction experiments were conducted using $\mathrm{CuK}_{\alpha}$ radiation in conjunction with a crystal monochromator and a flat photographic film. The sample contained in a sealed $0.5 \mathrm{~mm}$ Lindemann glass capillary was oriented by a magnetic field. Temperatures were maintained during any exposure (typically $15-20 \mathrm{~min}$ ) to a constancy of $0.1^{\circ} \mathrm{C}$ or better. The relative accuracy in the determination of the temperature variation of the layer spacing is reckoned to be $\pm 0.1 \AA$.

High pressure studies were conducted using an optical cell with sapphire windows, the sample being isolated from the pressure transmitting fluid by fluran. The transition temperatures were determined by the optical transmission technique. (For details regarding the experimental set-up used in the pressure studies see Refs. [7] and [8]). Pressure was measured to an accuracy of \pm 1 bar and temperature to $\pm 25 \mathrm{mK}$.

The dielectric constants were measured using a Hewlett-Packard Impedance Analyser (4 192 A) in the frequency range of $1 \mathrm{kHz}$ to $13 \mathrm{MHz}$. The sample, typically about $50 \mu \mathrm{m}$ thick and oriented by a magnetic field of $1.5 \mathrm{~T}$, was in a nitrogen environment during all measurements. The temperature of the sample was maintained constant to $\pm 25 \mathrm{mK}$ during the low frequency relaxation $\left(f_{\mathrm{R}}\right)$ measurements of $\varepsilon_{\|}$.

\section{Results and discussion.}

3.1 OptICAL MICROSCOPIC STUDIES. - The sample of DB90NO $\mathrm{Na}_{2}$ was synthesized in our laboratory. The purity of the material was ascertained by standard methods. All the transitions observed by the Bordeaux Group [6] were also seen by us by optical microscopy. In addition, we found evidence for the existence of another phase, over a temperature range of $4^{\circ} \mathrm{C}$ between the $\widetilde{\mathrm{C}}$ and $\mathrm{C}_{2}$ phases. This phase has been identified to be the $A_{2}$ phase as we shall see later. We shall discuss here only those observations which pertain to the observation of the $A_{2}$ phase. In figures $1 a-c$ we have shown the textures of the $\widetilde{\mathrm{C}}, \mathrm{A}_{2}$ and $\mathrm{C}_{2}$ phases evolved on cooling the focal conic texture of the $A_{1}$ phase. Figures $1 d-f$ show the textures obtained in these phases on cooling the homeotropically oriented domain of the $A_{1}$ phase. The textural changes on the formation of the $A_{2}$ phase are clearly seen in both sets of photographs, the homeotropic region of $A_{2}$ being particularly obvious.

It must be mentioned that the existence of the $\mathrm{A}_{2}$ phase as well as the second or lower temperature $\mathbf{N}_{\mathrm{re}}$. phase seemed to be strongly dependent on the purity of the sample; the impure samples failed to show either of these phases. The same effect was seen in samples heated repeatedly to high temperatures.

3.2 X-RAY STUDIES. - Variation of the layer spacing $(d)$ with temperature in the different phases of DB90NO $\mathrm{N}_{2}$ is shown in figure 2. These results are in good agreement with the earlier data of Hardouin et al. [5]. Starting from the high temperature $\mathrm{A}_{\mathrm{d}}$ phase $d$ increases smoothly from $1.24 l$ with decrease of temperature right through the transitions between the different $\mathrm{N}$ and $A_{d}$ phases. In the second reentrant nematic phase, modulations corresponding to both the partially bilayer and the monolayer periodicities are observed, the former modulation vanishing on going over to the $A_{1}$ phase. At the onset of the $A_{2}$ phase the bilayer as well as the monolayer periodicities corresponding to wavevectors $q_{0}$ and $2 q_{0}$ are seen. Both these periodicities show a decrease on going over to the $C_{2}$ phase, a trend similar to that seen near the $A_{2}-C_{2}$ transition of other compounds $[9,10]$. A feature of the $\mathrm{X}$-ray photographs was that the diffraction spots were quite 


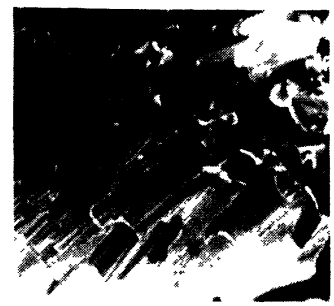

a)

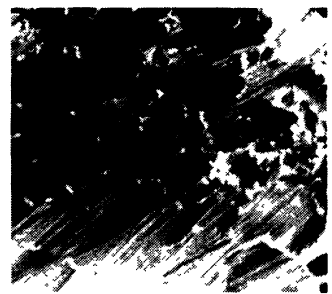

b)

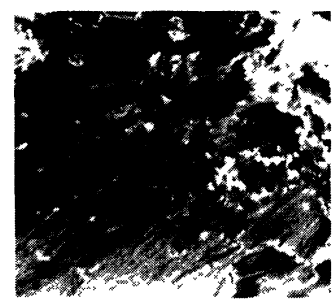

c)



d)

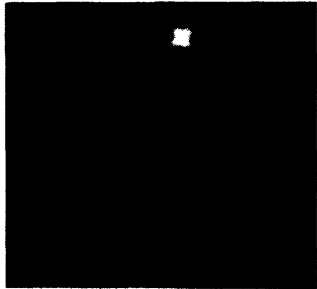

e)

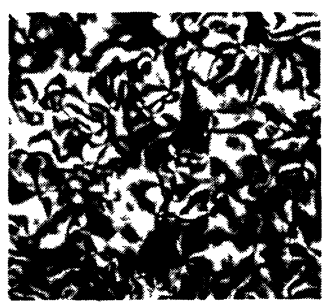

f)

Fig. 1. - Optical textures in the $\tilde{\mathrm{C}}, \mathrm{A}_{2}$ and $\mathrm{C}_{2}$ phases of $\mathrm{DB} 90 \mathrm{NO}_{2}$; crossed polars, $\mathrm{X} 250$. a-c : textures obtained on cooling a focal conic region of the $\mathrm{A}_{1}$ phase, (a) $103{ }^{\circ} \mathrm{C}, \widetilde{\mathrm{C}}$ phase, (b) $98^{\circ} \mathrm{C}, \mathrm{A}_{2}$ phase, (c) $92^{\circ} \mathrm{C}$, $\mathrm{C}_{2}$ phase. d-f : textures evolved on cooling a homeotropic domain of the $\mathrm{A}_{1}$ phase, (d) $114.6^{\circ} \mathrm{C}, \widetilde{\mathrm{C}}$ phase, (e) $98^{\circ} \mathrm{C}, \mathrm{A}_{2}$ phase, (f) $92.8^{\circ} \mathrm{C}, \mathrm{C}_{2}$ phase.



Fig. 2. - Temperature variation of the layer spacing $(d)$ in the different phases of $\mathrm{DB}^{-} \mathrm{ONO} \mathrm{N}_{2}$. The arrows in this figure as well as in the following figures represent the transition temperatures. 
sharp in both the reentrant nematic phases showing thereby that strong smectic-like local ordering exists in these phases.


phase boundaries (except the N-I phase boundary) is shown in figure 3. Owing to the limitations in the maximum working temperature of the high pressure cell, we did not monitor the N-I transition temperature as a function of pressure. The following features are seen from the $P$ - $T$ diagram :

(i) The $A_{d}$ as well as the $A_{d(r e)}$ phases are completely bounded in the $P-T$ plane, the phase boundaries being elliptic in shape similar to what is seen in other reentrant nematogens [7]. The maximum pressure of smectic stability $\left(P_{\mathrm{m}}\right)$ is $1.1 \mathrm{kbar}$ for the $\mathrm{A}_{\mathrm{d}}$ phase, and $0.29 \mathrm{kbar}$ for the $A_{d(r e)}$ phase. (ii) The $A_{1}-N_{r e}$ phase boundary is straight throughout in contrast to the two $A_{d}$ phases. This result which is similar to those observed earlier in other systems $[11,12]$ indicates that the pressure behaviour of the $A$ phase should be related to the extent of interdigitation of the molecules. (iii) Both $C_{2}$ and $A_{2}$ phases are suppressed at high pressures because of the intersection of the crystallization line with the $C_{2}-A_{2}$ and $A_{2}-\widetilde{C}$ phase boundaries respectively.

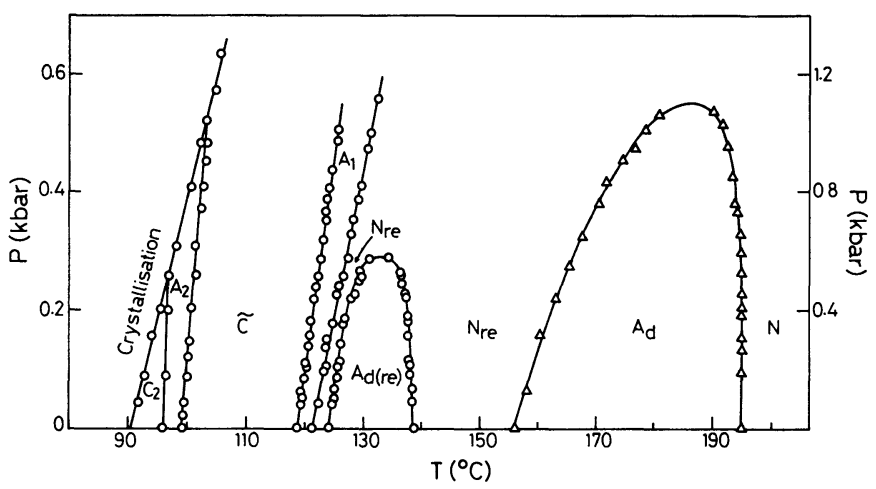

Fig. 3. - Pressure-temperature $(P-T)$ diagram of $\mathrm{DB} 90 \mathrm{NO}_{2}$. All transition temperatures were determined during the cooling mode. The pressure scale marked on the right is for data points shown as $\triangle$.

3.4 DiELECTRIC STUDIES. - Temperature variation of the static dielectric constants $\left(\varepsilon_{\|}\right.$and $\left.\varepsilon_{\perp}\right)$ as well as of the dielectric anisotropy $\Delta \varepsilon$ is shown in figure 4. It is seen that except at the highest temperature $\mathrm{N}-\mathrm{A}_{\mathrm{d}}$ transition, both $\varepsilon_{\|}$and $\varepsilon_{\perp}$ and hence $\Delta \varepsilon$ exhibit a smooth variation through all the other $A_{d}-N$ transitions. On approaching the $A_{1}$ phase $\varepsilon_{\|}$decreases while $\varepsilon_{\perp}$ increases causing thereby a pronounced decrease in $\Delta \varepsilon$. Owing to difficulties in obtaining homogeneous orientation in the $\mathrm{C}$ phases we have not made any measurements of $\Delta \varepsilon$ beyond the $\mathrm{A}_{1}$ phase.

Figure 5 gives a plot of $f_{\mathrm{R}} v s$. 1/T in all the mesophases of $\mathrm{DB} 90 \mathrm{NO}_{2}$. The corresponding activation energies are listed in table $I$. It is seen that the activation energy $(W)$ for the second or lower temperature $\mathrm{N}_{\text {re }}$ phase is significantly higher than the $W$ value of the first $\mathrm{N}_{\text {re }}$ phase which in turn is higher than that for the normal nematic phase. Similarly the activation energy of the reentrant $A_{d}$ phase is more than that of the normal $A_{d}$ phase. Amongst the four $A$ phases that exist for this compound, $\mathrm{A}_{1}$ has the highest $W$ while the normal $\mathrm{A}_{\mathrm{d}}$ has the lowest value. It must be mentioned that the Cole-Cole plots indicate the existence of a second dispersion close to the dispersion discussed here, but at frequencies higher than the maximum frequency $(13 \mathrm{MHz})$ capability of our instrument. The two representative Cole-Cole plots given in figure 6 for two temperatures clearly show that the second dispersion separates out more at the lower temperature 


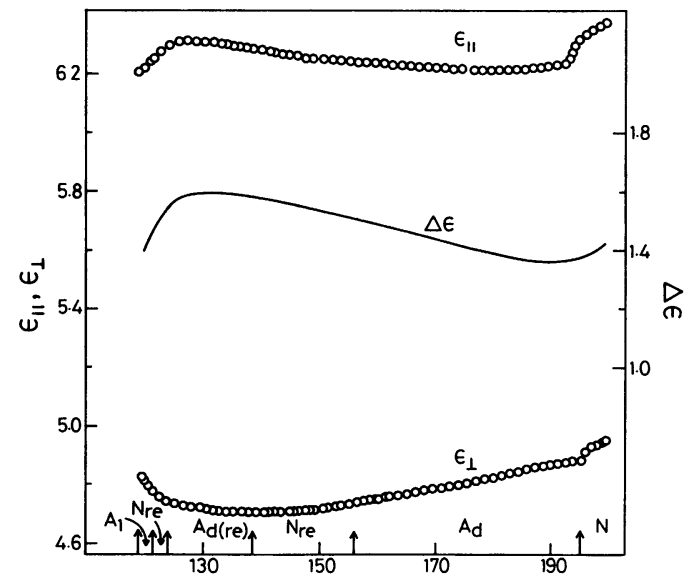

Fig. 4. - Variation of the principal dielectric constants $\left(\varepsilon_{\|}\right.$and $\left.\varepsilon_{\perp}\right)$ and the dielectric anisotropy $(\Delta \varepsilon)$ with temperature in the different phases of $\mathrm{DB} 90 \mathrm{NO}_{2}$.

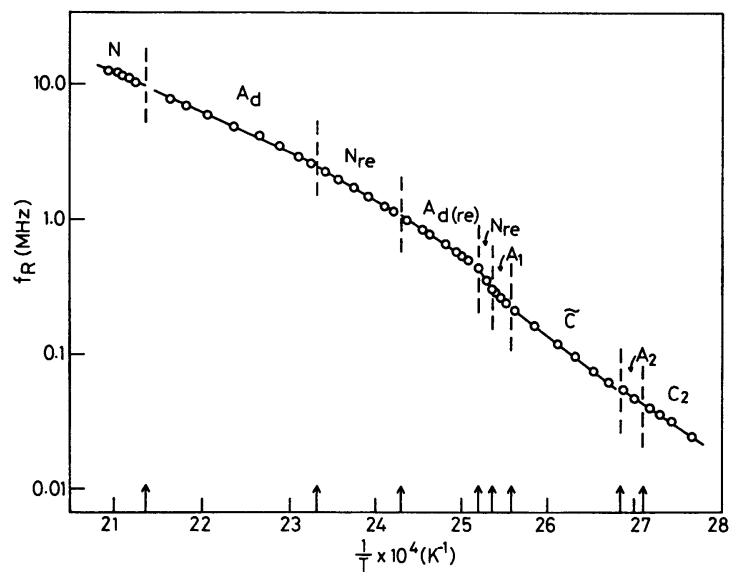

Fig. 5. - Plot of frequency of relaxation $\left(f_{\mathrm{R}}\right)$ versus $1 / T$ in the different phases of $\mathrm{DB} 90 \mathrm{NO}_{2}$.

Table I. - Activation energy $(W)$ corresponding to the low frequency dispersion of $\varepsilon_{\|}$in the different phases of $\mathrm{DB} 90 \mathrm{NO}_{2}$.

\begin{tabular}{|c|ccccccccc|}
\hline Phase & $\mathrm{N}$ & $\mathrm{A}_{\mathrm{d}}$ & $\mathrm{N}_{\mathrm{re}}$ & $\mathrm{A}_{\mathrm{d}(\mathrm{re})}$ & $\mathrm{N}_{\mathrm{re}}$ & $\mathrm{A}_{1}$ & $\tilde{\mathrm{C}}$ & $\mathrm{A}_{2}$ & $\mathrm{C}_{2}$ \\
\hline $\begin{array}{c}W \\
\text { in } \mathrm{eV}\end{array}$ & 0.54 & 0.63 & 0.74 & 0.87 & 1.88 & 1.23 & 0.97 & 0.86 & 0.86 \\
\hline
\end{tabular}

and as a consequence becomes more pronounced. Our determination of $f_{\mathbf{R}}$ at higher temperatures may have been conceivably affected by the overlapping of the two dispersion regimes at these temperatures. Attempts are underway to extend our measurements to higher frequencies in order to probe this second dispersion of $\varepsilon_{\|}$. 



Fig. 6. - Two representative Cole-Cole plots in the (a) $N_{r e}\left(148^{\circ} \mathrm{C}\right)$ and (b) $A_{d(r e)}\left(125^{\circ} \mathrm{C}\right)$ phases of $\mathrm{DB} 90 \mathrm{NO}_{2}$.

\section{Acknowledgments.}

We thank Professor S. Chandrasekhar for discussions and Mr. H. Subramonyam for his help in the pressure experiments.

\section{References}

[1] Cladis, P. E., Phys. Rev. Lett. 35 (1975) 48 ;

Cladis, P. E., Bogardus, R. K., Daniels, W. B. and Taylor, G. N., Phys. Rev. Lett. 39 (1977) 720.

[2] Madhusudana, N. V., Sadashiva, B. K. and Moodithaya, K. P. L., Curr. Sci. 48 (1979) 613.

[3] Hardouin, F., Sigaud, G., Achard, M. F. and Gasparoux, H., Phys. Lett. A 71 (1979) 347.

[4] For a comprehensive review of the compounds exhibiting the reentrant nematic behaviour see NGUYEN HuU Tinh, J. Chim. Phys. 80 (1983) 83.

[5] Hardouin, F., Levelut, A. M., Achard, M. F. and Sigaud, G., J. Chim. Phys. 80 (1983) 53.

[6] Nguyen Huu Tinh, Hardouin, F. and Destrade, C., J. Physique 43 (1982) 1127.

[7] Kalkura, A. N., Shashidhar, R. and Subramanya Raj Urs, M., J. Physique 44 (1983) 51.

[8] Kalkura, A. N., « High Pressure Optical Studies on Liquid Crystals ", Ph. D. Thesis, University of Mysore, 1982.

[9] Shashidhar, R., Suresh, K. A., Ratna, B. R., Krishna Prasad, S., Bahr, Ch., Oestreicher, A. and HePPKe, G., Mol. Cryst. Liq. Cryst. Lett., in press.

[10] Hardouin, F., Nguyen Huu Tinh and Levelut, A. M., J. Physique Lett. 43 (1982) L-779.

[11] Krishna Prasad, S., Shashidhar, R., Kalkura, A. N., Suresh, K. A., Heppke, G. and Hopf, R., Mol. Cryst. Liq. Cryst. 99 (1983) 185.

[12] Cladis, P. E., in " Liquid Crystals », Proc. Int. Liquid Cryst. Conf., Bangalore, December 1979, Ed. S. Chandrasekhar (Heyden, London) 1980, p. 105. 